\title{
APPROXIMATE CALCULATION OF ACTIVE RESISTANCE AND TEMPERATURE OF THE PULSE ELECTRIC ARC CHANNEL IN A HIGH-CURRENT DISCHARGE CIRCUIT OF A POWERFUL HIGH-VOLTAGE CAPACITOR ENERGY STORAGE
}

Purpose. To obtain calculation correlations for active resistance $\boldsymbol{R}_{c e}$ and maximal temperature $T_{m e}$ of plasma channel of pulse electric arc in the air double-electrode system (DES) with metal (graphite) electrodes, and also practical approbation of the obtained correlations for $R_{c e}$ and $T_{m e}$ in the conditions of high-voltage laboratory on the powerful capacity energy storage (CES) of electric setting, intended for reproducing on the electric loading of protracted $C$ - component of current of artificial lightning with the USA rationed on normative documents by amplitude-temporal parameters (ATP). Methodology. Electrophysics bases of high-voltage impulse technique, scientific and technical bases of development and creation of high-voltage high-current impulse electrical equipment, including powerful CES, and also measuring methods in discharge circuits of powerful high-voltage CES of pulse currents of millisecond temporal range. Results. On the basis of engineering approach the new results of approximate calculation of values of $R_{c e}$ and $T_{m e}$ are resulted in the plasma channel of pulse electric arc discharge in air DES of atmospheric pressure with metallic (graphite) electrodes. Practical approbation of results of calculation of values of $R_{c e}$ and $T_{m e}$ is executed as it applies to air DES, to connected in a discharge circuit of powerful high-voltage CES with protracted C-of component current of artificial lightning, characterized rationed ATP. It is shown that calculation of numeral value $R_{c e}$ approximately in 100 times exceeds the proper value of active resistance for the plasma channel of impulsive spark of electric discharge in air DES other things being equal, and a calculation of numeral value $T_{m e}$ well corresponds with the known thermodynamics information for classic electric arc in air DES of atmospheric pressure with graphite electrodes. Originality. New engineering approach is developed for the approximate calculation of values of $R_{c e}$ and $T_{m e}$ in electron-ion plasma of channel of pulse electric arc, arising in air DES of high-current discharge circuit of powerful high-voltage CES of proof-of-concept of electric setting of the technological setting. A formula is first obtained for the approximate calculation of equivalent active resistance of $R_{c e}$ of channel of pulse electric arc in air DES, remaining unchanging in the process of high-current discharge on RL-load of indicated CES. Practical value. Drawing on the got calculation results for the values of $R_{c e}$ and $T_{m e}$ in high-voltage impulse technique provides the rational choice of own electric parameters and construction elements of basic devices of powerful high-voltage CES of technological of electric setting, and also account of influence of electrical engineering descriptions of air DES on electromagnetic processes, taking place in the high-current discharge circuit of indicated CES with protracted C- of component current of artificial lightning. References 16, figures 6.

Key words: powerful high-voltage capacitor energy storage, air double-electrode system, pulse electric arc, active resistance of pulse electric arc channel, maximal temperature of pulse electric arc channel.

Приведены результаты расчетной оценки эквивалентного активного сопротивления $R_{c e}$ канала импульсного дугового электрического разряда в воздушной двухэлектродной системе (ДЭС) сильноточной разрядной цепи моцного высоковольтного емкостного накопителя энергии (ЕНЭ), используемого при моделировании в лабораторных условиях длительной С- компоненты тока искусственной молнии. Рекомендовано расчетное соотнощение для оценки максимальной электронной температуры $T_{m е}$ в низкотемпературной плазме канала импульсной электрической дуги в исследуемой воздушной ДЭС. Выполнена практическая апробация полученных соотношений для $\boldsymbol{R}_{c e} u T_{m e}$ применительно к воздушной ДЭС сильноточной разрядной цепи действующего мощного высоковольтного ЕНЭ генератора ГИТ-С, предназначенного для проведения испытаний технических объектов на электротермическую стойкость к воздействию длительной С- компоненты тока искусственной молнии с амплитудно-временными параметрами, соответствующими нормативным документам США SAE ARP 5412: 2013 и SAE ARP $5416: 2013$. Библ. 16, рис. 6.

Ключевые слова: мощный высоковольтный емкостный накопитель энергии, воздушная двухэлектродная система, импульсная электрическая дуга, активное сопротивление канала импульсной электрической дуги, максимальная температура канала импульсной электрической дуги.

Introduction. It is known that in gas-discharge gaps (for example, in air gaps of high-voltage air switches and other electrode systems of electrical loads) circuits of powerful capacitor energy storage devices (CES) designed to reproduce in the laboratory conditions of high-current electrophysical phenomena (for example, artificial lightning with pulse $A$ - and long-term $C$ - current components), both pulsed spark electric discharges and pulse arc electric charges can occur poisons [1-3]. For pulse spark electric discharges flowing in the air gaps of the discharge circuits of high-power high-voltage CES, the characteristic parameters are their duration $\tau_{p d} \leq 1 \mathrm{~ms}$ and the amplitude of their current $I_{m d} \leq 1000 \mathrm{kA}$ [1]. With regard to pulsed arc discharges in the discharge circuits of high-power high-voltage CES, for them the indicated electric parameters $\tau_{p d}$ and $I_{m d}$ are characterized by the following numerical values [2, 3]: $1000 \mathrm{~ms} \geq \tau_{p d} \geq 100 \mathrm{~ms}$ and $1000 \mathrm{~A} \geq I_{m d} \geq 100 \mathrm{~A}$. In the latter the numerical values of the parameters $\tau_{p d}$ and $I_{m d}$ practically correspond to the known characteristics of the classical electric arc 
discharge arising in the air double-electrode system (DES) between its cathode and anode at a constant or alternating current in the electric circuit [4]. According to the data given in $[4,5]$, the arc electric discharge in the air DES is maintained by thermionic emission from the surface of a metallic or graphite cathode electrode. Due to the acceleration of electrons in the interelectrode gap and the shock ionization of the air molecules between the cathode and the anode of the DES, a column (channel) of a brightly-luminous strongly ionized gas appears, called electron-ion plasma in electrophysics. For a classic example of an electric arc discharge in the open air between graphite (carbon) electrodes of a DES, the thermodynamic temperature of the arc channel with radius of up to $4 \mathrm{~mm}$ at constant current of $200 \mathrm{~A}$ on the anode surface in its central zone can reach a value of up to $4200 \mathrm{~K}$, and on the surface of the cathode - up to $3500 \mathrm{~K}[4,5]$.

In $[6,7]$, the results of an approximate calculation of the active resistance $R_{c}$ of the channel of pulse spark electric discharge between the metal electrodes of a highvoltage high-current air switch at atmospheric pressure were presented. Simple and convenient formulas for estimating the maximum temperature $T_{m e}$ of the electronion plasma of pulse electric arc in an air DES are not currently known to us. Of undoubted scientific and practical interest are the electrophysical problems associated with the design determination of the active resistance $R_{c e}$ and the maximum temperature $T_{m e}$ of the pulse arc electric discharge channel between the metallic (graphite) electrodes of the air DES in the high-current discharge circuit of the high-power high-voltage power testing unit of the electrical testing apparatus.

The goal of the paper is approximate calculation of the active resistance $R_{c e}$ and the maximum temperature $T_{m e}$ of the plasma channel of the pulsed arc electric discharge in the air DES that is part of the high-current discharge circuit of the powerful high-voltage CES, as well as the practical approbation of the calculation data in the conditions of the high-voltage laboratory on a real powerful CES of the electrical installation.

1. Problem definition. Let us consider an air DES located in a high-current discharge circuit of high-power high-voltage pulse current generator (PCG), whose CES is built on a single-module circuit based on parallelconnected high-voltage pulse capacitors. It is designed to reproduce in the air gap of length ha of a long-term $C$ component of artificial lightning current with normalized amplitude-time parameters (ATPs) according to the technical requirements of the current US regulatory documents SAE ARP 5412: 2013 and SAE ARP 5416: 2013 [8, 9]. Recall that the normalized ATPs for the aperiodic long-time $C$ - component of the lightning current have the following numerical values [8, 9]: current amplitude $I_{m d c}= \pm(200-800) \mathrm{A}$; the transferred electric charge $q_{d c}= \pm(200 \pm 40) \mathrm{C}$; duration of current flow $\tau_{p d c}=(0,25-1)$ s. It can be seen that the ATPs of this component of the artificial lightning current correspond to the main characteristics of the current of the electric arc discharge between the cathode and the anode of the air DES [4, 5]. We assume that the metallic or graphite electrodes of the DES are considered in atmospheric air under normal conditions (air pressure is $1.013 \cdot 10^{5} \mathrm{~Pa}$ and its temperature is $\theta_{0}=0{ }^{\circ} \mathrm{C}$ [4]). Taking into account the indicated numerical values of $\tau_{p d c}$, we use the plasma isothermicity condition in the channel of the considered electric arc, according to which its maximum electron temperature $T_{m e}$ will be practically equal to the maximum temperature $T_{m i}$ of the carriers of its ion current $\left(T_{m e} \approx T_{m i}\right)$ [4]. We assume that in the DES, the length $l_{c e}$ of the cylindrical channel of the equilibrium plasma of the pulsed electric arc is in the first approximation equal to the minimum length of the interelectrode gap in the investigated DES. We assume that in a high-current channel of an electric arc discharge in an air DES, the current density $\delta_{d c}$, the thermodynamic electron $T_{m e}$, and the ion temperature $T_{m i}$ of its equilibrium plasma are, in a first approximation, characterized by a practically uniform distribution along its radius. It is required, within the engineering approach, to obtain a new design ratio for the active resistance $R_{c e}$ and to recommend a simple formula for the estimated estimation of the maximum temperature $T_{m e}$ of the plasma of the pulse arc electric discharge channel in the air DES, and also to carry out practical approbation of the approximate calculations of the $R_{c e}$ and $T_{m e}$ values applied to the real high-current discharge circuit of an operating powerful PCG (PCG-C) simulating a long-tem $C$ - component of artificial lightning current on a low-resistance $R L$ - load.

2. Basic calculation relationships. Using the plasmodynamic method of calculating the value of $R_{c e}$ [6], for the variable in time $t$ active resistance of the plasma channel of a pulse arc of electric discharge in the air DES under study, we write the following expression:

$$
R_{c e}(t)=l_{c e}\left[\pi r_{c e}^{2}(t) \gamma_{c e}\right]^{-1}
$$

where $r_{c e}(t)$ is the changing in time $t$ radius of the plasma channel of the arc electric discharge between the metal (graphite) electrodes of the DES; $\gamma_{c e}$ is the average conductivity of low-temperature plasma in a cylindrical channel of pulse arc between DES electrodes.

It is known that the value $r_{c e}(t)$ during the course of the pulse discharge current $i_{d c}(t)$ of the powerful CES of the PCG- $C$ generator through the DES under investigation changes on the increasing part of the aperiodic current pulse from its minimum zero value (time $t=0$ ) to its maximum value $r_{c e m}$ corresponding to the instant $t_{m d c}$, when the current strength $i_{d c}(t)$ reaches its maximum value $I_{m d c}$. On the falling part of the indicated current pulse, the quantity $r_{c e}(t)$ varies from the maximum value $r_{c e m}$ (time instant $t_{m d c}$ ) to the minimum zero value corresponding to the moment when the pulse discharge current $i_{d c}(t)$ ceases to flow through the air DES (time $\left.t=\tau_{p d c}\right)$. Obviously, at the instants of time $t=0$ and $t=\tau_{p d c}$, the active resistance of the plasma channel of the pulsed arc electric discharge in the air DES takes, according to 
(1), infinitely large numerical values. In this connection, it is impossible to use directly the relation (1) for practical calculations of the value $r_{c e}(t)$. Therefore, we are faced with a new electrotechnical problem associated with the replacement of the variable in time $t$ with the value of the active resistance $r_{c e}(t)$ of the pulse electric arc by some equivalent value of its active resistance $R_{c e}$, which remains constant throughout the process of the impulse discharge current $i_{d c}(t)$ form through the considered DES. One of the possible ways of approximate solution of such a problem can be the averaging in (1) in time $t$ of the quantity $r_{c e}(t)$. Moreover, this is an unconventional averaging, when a time function of the form $f\left(r_{c e}\right)=r_{c e}{ }^{2}(t)$ is averaged on the right-hand side of expression (1). We have said about the limits of the change of this function above. Then, for the equivalent active resistance $R_{c e}$ of the pulsed arc electric discharge channel in the air DES, we obtain the relation:

$$
R_{c e}=l_{c e} /\left(\pi \gamma_{c e} r_{c e m}^{-1} \int_{0}^{r_{c e m}} r_{c e}^{2} d r_{c e}\right)=3 l_{c e}\left(\pi r_{c e m}^{2} \gamma_{c e}\right)^{-1} \text {. }
$$

It follows from (2) that in order to find the numerical value of the equivalent active resistance $R_{c e}$ of the arc discharge channel of length $l_{c e}$, it is necessary to know its two parameters such as the maximum radius $r_{c e m}$ and the average conductivity $\gamma_{c e}$ of the electron-ion plasma forming the column of the considered electric arc. The radius $r_{c e m}(\mathrm{~m})$ of the channel of pulse arc discharge in air DES depends on the strength of the discharge current $i_{d c}(t)$ of the high-power high-voltage generator PCG-C, flowing in it and for normal atmospheric conditions in the SI system is given in the form $[3,10]$ :

$$
r_{c e m}=1.1 \cdot 10^{-4}\left(I_{m d c}\right)^{1 / 2} .
$$

where $I_{m d c}$ is the amplitude (A) of the aperiodic long-term $C$ - current components of artificial lightning in the plasma channel of the pulse electric arc of DES.

Substituting (3) into (2), for the equivalent active resistance $R_{c e}(\Omega)$ of the plasma channel of the pulse electric arc in the DES of the high-current discharge circuit of the powerful high-voltage CES of the generator PCG-C, we obtain the following relation:

$$
R_{c e}=78.92 \cdot 10^{6} l_{c e}\left(I_{m d c} \gamma_{c e}\right)^{-1} .
$$

It follows from (4) that as the current $I_{m d c}$ increases in the discharge circuit of the powerful CES, the maximum voltage drop $U_{m d c}=R_{c e} I_{m d c}$ on the pulse electric arc in the air DES will decrease. This is due to the fact that the degree of ionization of the gas in its discharge gap will also increase with the increase of the current $I_{m d c}$ due to an increase in the thermionic emission from the cathode of the DES. The increase in the ionization of gas in the air discharge gap of the DES will result in increase in the average specific electric conductivity $\gamma_{c e}$ of the electron-ion plasma of the channel of the arc under investigation. As a result of these electrophysical processes in the gas-discharge gap of the air DES, according to (1), the equivalent active resistance $R_{c e}$ of its pulsed electric arc will be greatly reduced. As a result, this will lead to a decrease in the voltage $U_{m d c}$ on the pulsed electric arc in the air DES with an increase in the current amplitude $I_{m d c}$. The established feature corresponds to the character of the behavior of the arc discharge in the DES described in [4]. This circumstance indirectly indicates the reliability of the obtained calculated relation (4) for the equivalent active resistance of the plasma channel of a pulsed arc electric discharge in an air DES.

As for the quantitative values for the quantity $\gamma_{c e}$ entering into (4), according to the calculated experimental data, they are numerically approximately $5000(\Omega \cdot \mathrm{m})^{-1}$ in the first approximation, taking into account (2). We will point out that for the highly ionized electron-ion plasma of the channel of pulse arc electric discharge in the air DES, the upper limit of the numerical values of $\gamma_{c e}$ can reach a level of the order of $20 \cdot 10^{3}(\Omega \cdot \mathrm{m})^{-1}[1,6]$.

In the calculated estimate of the largest electron temperature $T_{m e}$ in the electron-ion equilibrium plasma of a pulse arc discharge for an air DES, taking into account the assumptions made (3) and the thermophysical approach given in [12], the following approximate expression can be recommended:

$$
T_{m e} \approx 95.35 \cdot \sqrt[4]{U_{a c} / \sigma_{c}}
$$

where $\sigma_{c}=5.67 \cdot 10^{-8} \mathrm{~W} \cdot\left(\mathrm{m}^{2} \cdot \mathrm{K}^{4}\right)^{-1}$ is the Stefan-Boltzmann constant [4]; $U_{a c} \leq 11 \mathrm{~V}$ is the near-electrode voltage drop in the air DES with metal (graphite) electrodes (for the graphite anode $U_{a c} \approx U_{a} \approx 11 \mathrm{~V}$, and for the graphite cathode $\left.U_{c} \approx 10 \mathrm{~V}[5]\right)$.

3. Powerful high-voltage CES of the generator PCG- $C$ and its application for testing technical objects for lightning resistance. Fig. 1, 2 show the principal circuit diagram and the general view of the powerful CES of the generator PCG- $C$ used in experimental studies of electrothermal lightning strength of test objects (TO) of various elements (for example, metal or composite plating) of various technical objects (for example, aircraft). The own electrical parameters of the discharge circuit of the generator PCG- $C$ were equal [2]: the resistance is $R_{C} \approx 4.74 \Omega$; inductance $L_{C} \approx 11.43 \mathrm{mH}$; capacitance is $C_{C} \approx 45.36 \mathrm{mF}$.

A powerful single-module CES of the PCG- $C$ generator was assembled on the basis of 324 parallelconnected high-voltage pulse capacitors of the ИМ -5-140 type (rated voltage $\pm 5 \mathrm{kV}$, nominal capacity $140 \mu \mathrm{F}$ ) $[2,13]$. The nominal value of the stored electrical energy in the CES of the PCG-C generator was $W_{C 0} \approx 567 \mathrm{~kJ}[2]$. In accordance with Fig. 1 in the circuit of the generator of high-voltage ignition pulses (GHIP), a two-electrode air switch $F_{1}$ with massive basic steel electrodes for voltage up to $\pm 50 \mathrm{kV}$ was installed and in the discharge circuit of the generator PCG- $C$ a high-voltage two-electrode air switch $F_{2}$ of the ВДВК-10 type with rectangular graphite electrodes for voltage of up to $\pm 10 \mathrm{kV}$ [14] (Fig. 3). 


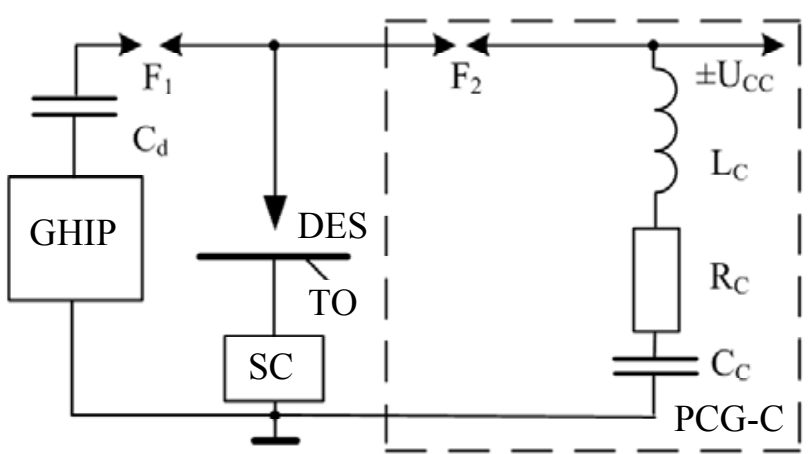

Fig. 1. The principal electrical circuit diagram of the highcurrent discharge circuit of the powerful high-voltage CES of the generator PCG- $C$, used to study the effect of the arc channel on the TO of the metal cladding of a technical object (GHIP generator of high voltage ignition pulses of voltage amplitude up to $\pm 100 \mathrm{kV} ; F_{1}, F_{2}$ - two-electrode high-voltage air spark switches; $C_{\mathrm{d}}$ - separation capacitance of $180 \mathrm{pF}$ and for impulse voltage of up to $\pm 120 \mathrm{kV}$ in the GHIP circuit, which controls the operation of the switches $F_{1}$ and $F_{2}$; DES - double-electrode system with air gap; TO - a test specimen of the metal skin of the object; SC - shunt of coaxial type ШК-300 for measuring the current of pulse electric arc in the air gap of DES and TO;

$\pm U_{C C}$ - charging voltage of high-voltage capacitors of the generator PCG- $C ; L_{C} \approx 11.43 \mathrm{mH}, R_{C} \approx 4.74 \Omega, C_{C} \approx 45.36 \mathrm{mF}$ own electrical parameters of the generator, including inductance, active resistance and capacitance of its high-current discharge circuit)

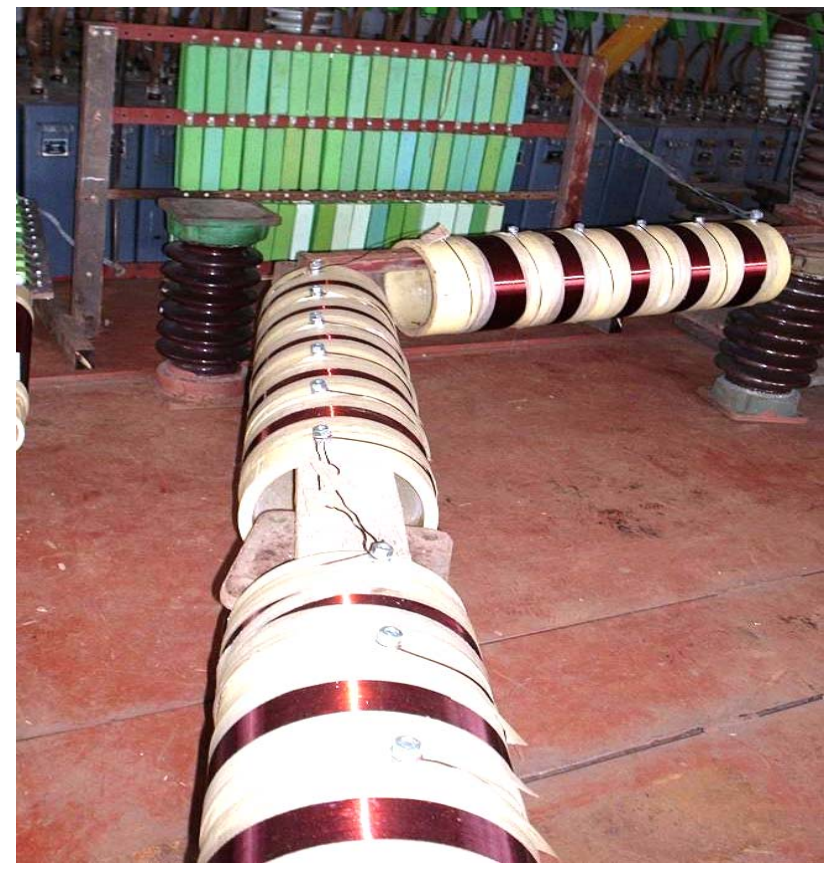

Fig. 2. General view of the powerful CES of the high-voltage generator PCG- $C$ (in the foreground are the forming activeinductive elements of its high-current discharge circuit, and in the background - the parallel-connected high-voltage pulse capacitors ИМ-5-140) [2, 3]

In practical approbation of the calculated ratios (4) and (5) with reference to the high-current discharge circuit of the PCG- $C$ generator, an air DES was used, schematically shown in Fig. 4. To initiate an electrical breakdown of the air gap $h_{a}$ in this DES and in accordance with the requirements of [8, 9], a thin copper electrically exploding wire (EEW) was used, having radius of $r_{e} \approx 0.1 \mathrm{~mm}$ and length $l_{e} \approx 37 \mathrm{~mm}$. The air working gaps $h_{a}$ and $h_{e}$ in this DES were 14 and $1 \mathrm{~mm}$, respectively. In Fig. 5, in enlarged form, the external view of the air DES used in the high-voltage discharge circuit of the powerful CES of the high-voltage generator PCG- $C$ is shown.

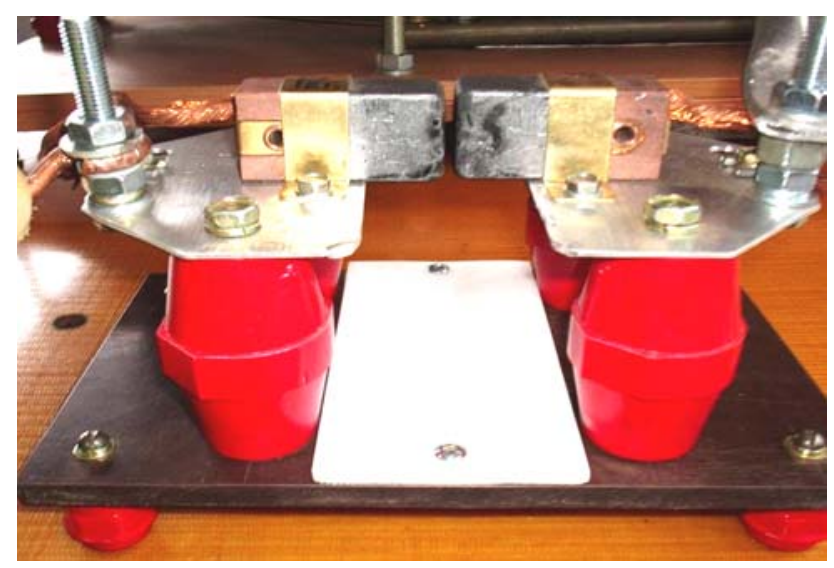

Fig. 3. External view of high-voltage two-electrode air switch type ВДВК-10 with graphite electrodes of rectangular shape for voltage up to $\pm 10 \mathrm{kV}$ used in the discharge circuit of the generator PCG- $C$ [2]

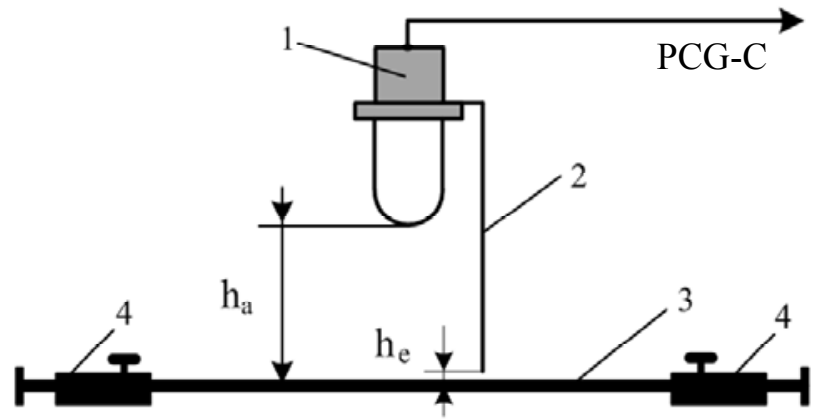

Fig. 4. General view of the air DES in the high-current discharge circuit of the generator PCG- $C$ ( 1 - the upper massive

cylindrical steel electrode; 2 - the round thin copper EEW;

3 - the lower massive flat electrode which is the metal shell of the technical object; 4 - the massive rectangular aluminum electrodes intended for rigid double-sided fastening in their grooves of a flat TO; $h_{a}$ - the length of the air gap in the DES;

$h_{e}$ - the length of the air gap between the lower edge of the copper EEW and the outer flat surface of the TO)

The charging voltage of the high-voltage capacitors of the high-power CES of the generator PCG- $C$ for choosing the appropriate experiments was chosen with negative polarity equal to $U_{C C} \leq 4.2 \mathrm{kV}$. The choice of the polarity of the charging voltage $U_{C C}$ was determined by the necessity to simulate the most severe conditions in the electrothermic sense in the investigated DES and, accordingly, in the circular zone of the fastening of a high-current cylindrical plasma channel of a pulsed electric arc with a long-term $C$ - component of the artificial lightning current on the outer flat surface of the metal structure of the technical object. To prevent 


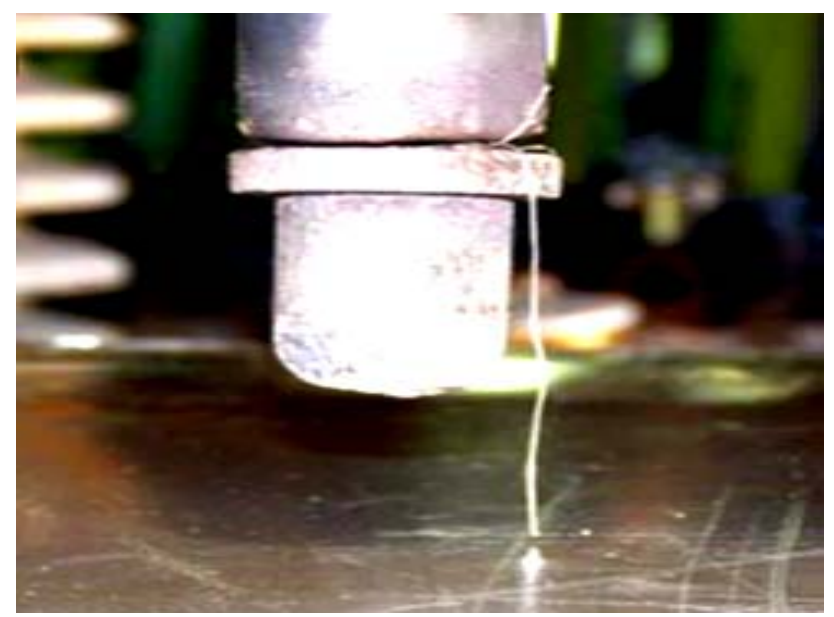

Fig. 5. Enlarged appearance of the air DES with a thin copper EEW on the desktop of the high-voltage generator PCG- $C$ with powerful CES when tested in its highcurrent discharge circuit of the TO sheet metal plating of the technical object for electrothermal resistance to direct action on it for a long-term $C$ - components of artificial lightning current with normalized ATPs $\left(h_{a} \approx 14 \mathrm{~mm} ; h_{e} \approx 1 \mathrm{~mm} ; r_{e} \approx 0.1 \mathrm{~mm}\right.$; $l_{e} \approx 37 \mathrm{~mm}$ ) [10]

mechanical damage in a high-power capacitor bank of the PCG- $C$ generator and to provide the required safety precautions for the high-voltage CES personnel undergoing maintenance by it during emergency operation (for example, with an electrical breakdown of the insulation of at least one of the 324 mentioned capacitors when they are charged or discharged) on all high-voltage terminals of the used capacitors of the CES of the generator PCG- $C$, protective resistances were constructed, made of high-voltage permanent graphiteceramic resistors type TBO-60 at constant voltage up to $\pm 25 \mathrm{kV}[2,15]$.

In the high-voltage CES of the generator PCG- $C$ on the high-voltage terminals of each of 324 pcs of its capacitors type ИМ-5-140 to one protective resistor TBO-60-100 $\Omega[2,15]$ were fixed.

Synchronous operation of the spark switches $F_{1}$ and $F_{2}$ in the circuit in Fig. 1 was carried out by feeding a microsecond voltage pulse with amplitude up to $\pm 100 \mathrm{kV}$ $[2,14]$ through a high-voltage separation capacitor $C_{d}$ to a spherical steel electrode $30 \mathrm{~mm}$ in diameter of the switch $F_{1}$ from the GHIP.

In the case of an electric breakdown from the GHIP of the air working gap of the spark switch $F_{1}$ and its subsequent operation, the resulting pulse overvoltage on the DES with the TO leads to an almost simultaneous operation with it and a spark switch $F_{2}$. After the spark switches $F_{1}, F_{2}$, the electric breakdown of the air gap of length $h_{e} \approx 1 \mathrm{~mm}$ and the electrical explosion of a thin copper wire in the zone of the DES are triggered by the discharge of the pre-charged high-voltage capacitors of the CES generator PCG- $C$ through the air DES and the metal shell of the technical object, long-term $C$ - current components of artificial lightning with the required $[8,9]$ ATPs. Measurement of ATP for the long-term $C$ - components of the current of artificial lightning in the channel of the electric arc in the aerial DES and the metal shell of the object were carried out using a measuring coaxial shunt of the ШК-300 type [2,14] certified by the state metrological service, having a conversion factor of $K_{C} \approx 5642 \mathrm{~A} / \mathrm{V}$, and a digital storage oscilloscope Tektronix TDS 1012.

4. Results of experimental approbation of calculations of active resistance and temperature of the channel of pulse electric arc in the air DES. According to Fig. 1 and the above scientific and technical materials in the considered high-current discharge circuit of the powerful high-voltage generator of the PCG- $C$ generator there are two air power plants connected in a common electrical circuit: the first one is directly in the zone of the TO placement of the sheet metal covering of the technical object with the air gap $h_{a} \approx 14 \mathrm{~mm}$; the second one - in the zone of the spark switch $F_{2}$ with an interelectrode gap of air of length $h_{a k} \approx 4 \mathrm{~mm}$. It is the total air gap of these two DES with length $l_{c e}=\left(h_{a}+h_{a k}\right)$ and will determine the minimum total length of the pulsed electric arc channel in the high-current circuit of the powerful high-voltage CES of the generator PCG- $C$ and, accordingly, its minimum total active resistance $R_{c e}$. In Fig. 6 shows the oscillogram of a long-term $C$ - component of the current of artificial lightning flowing through the above air DES and the metal shell of the object.

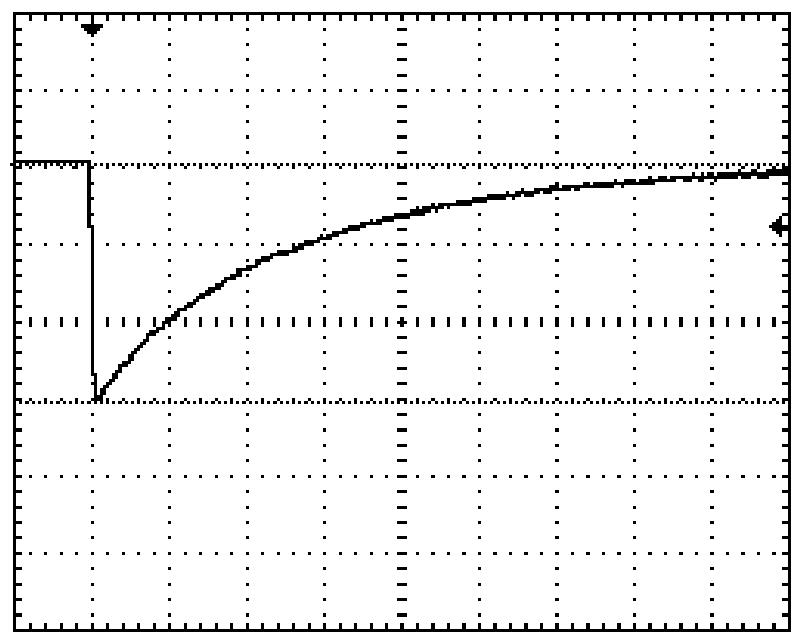

Fig. 6. The oscillogram of the long-term $C$ - component of the current of artificial lightning with normalized ATPs in the highcurrent circuit of the PCG- $C$ generator at the discharge of its powerful CES on the air DES with an electrically exploding thin copper wire $\left(r_{e}=0.1 \mathrm{~mm} ; l_{e}=37 \mathrm{~mm}\right)$ and sheet TO from aluminum $\mathrm{AM} 2 \mathrm{M}$ alloy of $2 \mathrm{~mm}$ thickness $\left(U_{c c} \approx-4.2 \mathrm{kV}\right.$; $W_{C} \approx 400 \mathrm{~kJ} ; I_{m d c} \approx-0.869 \mathrm{kA} ; t_{m d c} \approx 9 \mathrm{~ms} ; \tau_{p d c} \approx 1000 \mathrm{mc} ; q_{d c} \approx 192 \mathrm{C}$; vertical scale: $282 \mathrm{~A} /$ cell; horizontal scale - $100 \mathrm{~ms} /$ cell)

From the data in Fig. 6 that the ATP used in the experiments of the long-term $C$ - current component of the artificial lightning correspond to the requirements $[8,9]$ and to the characteristics of the pulse arc electric discharge in this air DES. Assuming that $\gamma_{c e} \approx 5 \cdot 10^{3}(\Omega \cdot \mathrm{m})^{-1}$ [11], $l_{c e} \approx 18 \cdot 10^{-3} \mathrm{~m}$ and $I_{m d c} \approx 869 \mathrm{~A}$, from (4) we find that 
in the considered experimental case the total equivalent active resistance of the plasma channel of pulse electric arc in the investigated air DES will be not less than $R_{c e} \approx 0.327 \Omega$. The resulting calculated value of $R_{c e}$ will be up to $7 \%$ of the intrinsic active resistance of the $R_{C}$ of the discharge circuit of the powerful high-voltage generator of the PCG- $C$ generator. Taking into account the data obtained in [6], it can be concluded that for identical values of $l_{c e}$ and average plasma specific conductivity, equal to $\gamma_{c e} \approx 5 \cdot 10^{3}(\Omega \cdot \mathrm{M})^{-1}$, in atmospheric air pressure of the high-current circuit of the powerful high-voltage CES, the equivalent active resistance of the pulse arc electric discharge channel at $I_{m d c} \approx 0.869 \mathrm{kA}\left(t_{m d c} \approx 9 \mathrm{~ms} ; \tau_{p d c} \approx 1 \mathrm{~s}\right)$ will be approximately 100 times greater than the equivalent active resistance of the channel of pulse spark electric discharge at $I_{m d} \approx 202 \mathrm{kA}\left(t_{m d} \approx 36 \mu \mathrm{s} ; \tau_{p d} \approx 0.5 \mathrm{~ms}\right)$. This result is explained for $R_{c e}$ in that for the specified ATPs the millisecond (with the amplitude $I_{m d c}$ ) and the microsecond (with amplitude $I_{m d}$ ) currents in the air DES, the maximum radius in (3) $r_{\text {cem }} \approx 3.24 \mathrm{~mm}$ of the pulsed arc electric discharge channel turns out to be other things equal Conditions is practically an order of magnitude smaller than the maximum radius $r_{c m} \approx 32.7 \mathrm{~mm}$ of the pulsed spark electric discharge channel, which satisfies the Braginsky formula for high currents of microsecond duration $[1,7,16]$.

At $U_{a c} \approx U_{a} \approx 11 \mathrm{~V}$ from the formula (5), we obtain that in the high-current experiment under consideration with the use of a powerful high-voltage CES of the PCG- $C$ generator, the maximum electron temperature $T_{m e}$ of an equilibrium electron-ion plasma in a cylindrical channel of pulse arc discharge in an air DES for the switch type ВДВК-10 $\left(l_{c e} \approx 4 \mathrm{~mm}\right)$ is approximately $11250 \mathrm{~K}$. It can be seen that the calculated numerical value of the electron temperature $T_{m e}$ of the plasma in the brightly shining column (channel) of the pulsed electric arc near the graphite anode of the above air DES is in good agreement with the known thermodynamic data typical for the near-axis region of the classical arc discharge flowing in an air DES with graphite electrodes at atmospheric pressure and $200 \mathrm{~A}$ current $[4,5]$. In this case, according to [5], in the near-axis zone of the «coal» («graphite») $\operatorname{arc}\left(l_{c e} \approx 46 \mathrm{~mm}\right)$, which freely «burns» in the air DES, the temperature of its equilibrium plasma is about $10^{4} \mathrm{~K}$, and near the cathode $-1.2 \cdot 10^{4} \mathrm{~K}$.

\section{Conclusions.}

1. A new relation (4) is obtained for approximate calculation of the equivalent active resistance $R_{c e}$ of the plasma channel of pulse electric arc in air DES of the high-current discharge circuit of a powerful high-voltage CES of a test electrophysical installation generating the long-term $C$ - component of artificial lightning current.

2. For the calculated estimate of the maximum electron temperature $T_{m e}$ in equilibrium electron-ion lowtemperature plasma of pulse arc electric discharge in the air DES with metallic (graphite) electrodes used in the described experiments of the powerful high-voltage CES of the generator PCG- $C$, it is recommended that electrical engineers use the approximate formula (5).

3. High-voltage experiments carried out at the Scientific-\&-Research Planning-\&-Design Institute «Molniya» of the NTU «KhPI» on a powerful highvoltage CES of the PCG- $C$ generator, which reproduces on the low-resistance load the long-term $C$-component of the current of artificial lightning with normalized ATPs in accordance with the current requirements of the US regulatory documents SAE ARP 5412: 2013 and SAE ARP 5416: 2013, confirmed the validity of the proposed calculation relationships (4) and (5) for determining the electrical and thermal physical values of $R_{c e}$ and $T_{m e}$ in the plasma channel of the pulsed arc discharge in air DES.

\section{REFERENCES}

1. Dashuk P.N., Zayents S.L., Komel'kov V.S., Kuchinskiy G.S., Nikolaevskaya N.N., Shkuropat P.I., Shneerson G.A. Tehnika bol'shih impul'snyh tokov i magnitnyh polej [Technique large pulsed currents and magnetic fields]. Moscow, Atomizdat Publ., 1970. 472 p. (Rus).

2. Baranov M.I., Koliushko G.M., Kravchenko V.I., Nedzel'skii O.S., Dnyshchenko V.N. A Current Generator of the Artificial Lightning for Full-Scale Tests of Engineering Objects. Instruments and Experimental Technique, 2008, no.3, pp. 401405. doi: 10.1134/s0020441208030123.

3. Baranov M.I. Izbrannye voprosy elektrofiziki. Tom 2, Kn. 2: Teoriia elektrofizicheskikh effektov i zadach [Selected topics of Electrophysics. Vol.2, Book 2. A theory of electrophysical effects and tasks]. Kharkiv, Tochka Publ., 2010. 407 p. (Rus).

4. Kuz'michev V.E. Zakony i formuly fiziki [Laws and formulas of physics]. Kiev, Naukova Dumka Publ., 1989. 864 p. (Rus).

5. Raiser Yu.P. Fizika gazovogo razryada [Physics of gas discharge]. Moscow, Nauka Publ., 1987. 592 p. (Rus).

6. Baranov M.I. A close calculation of active resistance of plasma channel of a spark digit is in the high-voltage heavycurrent air switchboard of atmospheric pressure. Bulletin of NTU «KhPI». Series: "Technique and electrophysics of high voltage», 2017, no.15(1237), pp. 5-11. (Rus).

7. Baranov M.I., Rudakov S.V. An approximate calculation of energy dissipation and electric erosion of electrodes in the highvoltage high-current air switch of atmospheric pressure. Electrical engineering \& electromechanics, 2017, no.3, pp. 3239. doi: 10.20998/2074-272X.2017.3.05.

8. SAE ARP 5412: 2013. Aircraft Lightning Environment and Ralated Test Waveforms. SAE Aerospace. USA, 2013. pp. 1-56.

9. SAE ARP 5416: 2013. Aircraft Lightning Test Methods. SAE Aerospace. USA, 2013. - pp. 1-145.

10. Abramov N.R., Kuzhekin I.P., Larionov V.P. Characteristics of penetration of the walls of metal objects when exposed to lightning. Electricity, 1986, no.11, pp. 22-27. (Rus).

11. Baranov M.I. Izbrannye voprosy elektrofiziki. Tom 3: Teorija i praktika elektrofizicheskih zadach [Selected topics of Electrophysics. Vol. 3: Theory and practice of electrophysics tasks]. Kharkiv, Tochka Publ., 2014. 400 p. (Rus).

12. Baranov M.I. An approximate calculation of the maximum temperature of the plasma in high-current high-voltage spark discharge channel switch air atmospheric pressure. Tekhnichna Elektrodynamika, 2010, no.5, pp. 18-21. (Rus).

13. Berzan V.P., Gelikman B.Yu., Guraevsky M.N., Ermuratsky V.V., Kuchinsky G.S., Mezenin O.L., Nazarov N.I., 
Peregudova E.N., Rud' V.I., Sadovnikov A.I., Smirnov B.K., Stepina K.I. Elektricheskie kondensatory i kondensatornye ustanovki. Spravochnik [The electrical capacitors and condenser options. Directory]. Moscow, Energoatomizdat Publ., 1987, 656 p. (Rus).

14. Baranov M.I., Koliushko G.M., Kravchenko V.I., Nedzel'skii O.S., Nosenko M.A. High-voltage high-current airfilled spark gaps of an artificial-lightning-current generator. Instruments and Experimental Techniques, 2008, vol.51, no.6, pp. 833-837. doi: 10.1134/s0020441208060109.

15. Baranov M.I., Rudakov S.V. Development of new charts of capacitance-resistance defense of high-voltage capacitors of powerful capacity stores of energy from emergency currents. Electrical engineering \& electromechanics, 2015, no.6, pp. $47-$ 52. (Rus). doi: 10.20998/2074-272X.2015.6.08.

16. Lozanskiy E.D., Firsov O.B. Teorija iskry [Theory of spark]. Moscow, Atomizdat Publ., 1975. 272 p. (Rus).

\section{Received 20.04.2017}

How to cite this article:

Baranov M.I., Rudakov S.V. Approximate calculation of active resistance and temperature of the pulse electric arc channel in a high-current discharge circuit of a powerful high-voltage capacitor energy storage. Electrical engineering \& electromechanics, 2017, no.4, pp. 42-48. doi: 10.20998/2074-272X.2017.4.07.
M.I. Baranov ${ }^{1}$, Doctor of Technical Science, Chief Researcher, S.V. Rudakov ${ }^{2}$, Candidate of Technical Science, Associate Professor,

${ }^{1}$ Scientific-\&-Research Planning-\&-Design Institute «Molniya», National Technical University «Kharkiv Polytechnic Institute», 47, Shevchenko Str., Kharkiv, 61013, Ukraine, phone +380577076841 ,

e-mail: baranovmi@kpi.kharkov.ua

${ }^{2}$ National University of Civil Protection of Ukraine, 94, Chernyshevska Str., Kharkiv, 61023, Ukraine, phone +38057 7073438,

e-mail: serg_73@i.ua 